\title{
Patients Retransitioning from Biosimilar TNFa Inhibitor to the Corresponding Originator After Initial Transitioning to the Biosimilar: A Systematic Review
}

\author{
Rosanne W. Meijboom ${ }^{1,2} \cdot$ Helga Gardarsdottir ${ }^{2,3,4} \cdot$ Toine C. G. Egberts $^{2,3} \cdot$ Thijs J. Giezen $^{1,2,5}$ (D)
}

Accepted: 2 November 2021 / Published online: 6 December 2021

(c) The Author(s) 2021

\begin{abstract}
Background Transitioning patients from an originator to a corresponding biosimilar has been extensively studied in both randomized controlled trials and observational studies. Although transitioning is considered well-tolerated, with no negative impacts on efficacy and/or safety, 2.6-25.8\% of patients restart treatment with the originator (retransitioning). Retransitioning to the originator can be considered an indication of biosimilar treatment failure or dissatisfaction with biosimilar treatment. Increasing our knowledge of patients who retransition might help to reduce the number of patients retransitioning.

Objective Our objective was to estimate the cumulative incidence of patients who retransitioned from a tumor necrosis factor (TNF)- $\alpha$ inhibitor biosimilar to originator and to explore potential patient, disease, and treatment and implementation strategy factors associated with retransitioning.

Method We conducted a systematic literature search in the PubMed, EMBASE, and Cochrane Central Register of controlled trials databases until March 2021. Studies on TNF $\alpha$ inhibitors, biosimilar transitioning, and retransitioning were included. Transitioning was defined as switching from an originator to a biosimilar, and retransitioning was defined as switching from an originator to a biosimilar and back to the originator. Characteristics of the studies were descriptively analyzed. Studies were weighted by the number of patients transitioning, and the primary outcome was the median cumulative incidence of retransitioning. For each of the factors related to patient, disease, and treatment and implementation strategy, studies were stratified according to the categories of that factor. The weighted medians and interquartile ranges (IQRs) of the cumulative incidence of retransitioning in these studies were calculated and compared to explore whether a potential association existed between these factors and the cumulative incidence of retransitioning.

Results Of 994 screened publications, 37 were included. The weighted median cumulative incidence of retransitioning was 7.6\% (IQR 6.8-17.2). Studies that included only patients with inflammatory bowel disease (6.6 vs. 15.1-17.7\% for other indications), included only patients with stable disease ( 7.0 vs. $13.7 \%$ for including all patients), and did not offer retransitioning at the introduction of the biosimilar ( 7.0 vs. $11.1 \%$ for studies that offered retransitioning) reported less retransitioning. In addition, the incidence of retransitioning was lower when extra laboratory monitoring was part of the implementation strategy ( 1.6 vs. $6.1 \%$ ) and when gainsharing (patients' healthcare directly benefits from financial savings from transitioning) (1.4 vs. $7.2 \%$ for studies without gainsharing) was applied.

Conclusions In studies on transitioning patients from TNF $\alpha$ originator to biosimilar, $8 \%$ of patients retransitioned. Retransitioning appeared to be lower in studies that included only patients with stable disease and in studies that did not offer patients the option of retransitioning at the introduction of the biosimilar. In addition, retransitioning appeared to be lower in studies that implemented extra laboratory monitoring as part of the biosimilar implementation strategy. Clinicians should consider implementing these suggestions as they might reduce retransitioning rates and improve the introduction of biosimilars in clinical practice.
\end{abstract}

PROSPERO registration ID: CRD42021226381

\section{Introduction}

Tumor necrosis factor (TNF)- $\alpha$ inhibitors are currently the cornerstone treatment for several immune-mediated diseases such as rheumatoid arthritis and inflammatory bowel disease 


\section{Key Points}

Studies of patients transitioning from tumor necrosis factor- $\alpha$ inhibitor originator to a biosimilar reported that about $8 \%$ of such patients retransitioned. Retransitioning was defined as switching from the originator to a biosimilar and back to the originator.

The following factors might result in fewer patients retransitioning: only transitioning patients with stable disease; not actively offering patients the option to retransition if they are dissatisfied with the biosimilar; and including extra laboratory monitoring as part of the biosimilar implementation strategy.

(IBD) [1-3]. At the time they were introduced, these treatments were a very effective but costly treatment modality. The introduction of biosimilars ("a biological medicinal product that contains a version of the active substance of an already authorized biological medicinal product [originator]" [4]) several years ago lowered the price of TNF $\alpha$ inhibitor treatment and improved patient access to these treatments [5]. Biosimilars for three TNF $\alpha$ inhibitors are currently approved. The first infliximab biosimilar was approved in 2015 in Europe [6] and in 2016 in the USA [7], the first etanercept biosimilar was approved in 2016 in both Europe and the USA [7, 8], and the first adalimumab biosimilar was approved in 2018 in Europe [9] and in 2016 in the USA [7].

The similarity of biosimilars in terms of quality, efficacy, and safety, including immunogenicity, must be thoroughly demonstrated in an extensive comparability exercise in which physiochemical properties, biological activity, immunochemical properties, and in vivo pharmacological properties are compared between originator and biosimilar [4]. Similarity is confirmed in at least one randomized controlled trial (RCT) where TNF $\alpha$ inhibitor-naïve patients are randomized between the originator and the corresponding biosimilar [10-12]. Since biosimilars have properties similar to those of their originators, it is expected that patients already treated with the originator can transition to the biosimilar without any impact on the efficacy, safety, and immunogenicity of their treatment. This has been confirmed in several RCTs, including the NOR-SWITCH study, in which 241 patients receiving originator infliximab were randomized to continuing originator or transitioning to the biosimilar. Disease worsening was reported in $26 \%$ of the patients who remained on the originator and in $30 \%$ of patients who transitioned to the biosimilar, which was within the prespecified
$15 \%$ inferiority margin [13]. Other double-blinded RCTs involving TNF $\alpha$ inhibitors also demonstrated noninferiority between remaining on an originator and transitioning to a biosimilar [14].

Transitioning from originator to biosimilar has also been extensively studied for different biologicals in several therapeutic indications in observational studies. Within these studies, infliximab was the most frequently studied biosimilar. Overall, these studies concluded that there were no major safety issues, including immunogenicity, after transitioning [14]. However, some studies have shown that patients who transitioned to a biosimilar experienced loss of effect and/ or adverse events (AEs), resulting in higher discontinuation rates than in patients who remained on the originator [15-18]. It has also been shown that, of all patients who transitioned from originator to biosimilar, 2.6-25.8\% restarted treatment with the originator (retransitioning) [16, 19]. Retransitioning to the originator can be considered an indication of biosimilar treatment failure or dissatisfaction with biosimilar treatment [20]. Retransitioning in these studies was mainly driven by patient-reported outcomes, such as subjective AEs, with no differences in objective clinical parameters. Thus, the authors attributed this to the nocebo effect (i.e., patients' negative expectations leading to AEs being experienced or a perceived decrease in response) [14, 21].

However, the different percentages of retransitioning in these studies might also be related to factors other than the nocebo effect. For example, since RCTs apply extensive inclusion and exclusion criteria compared with observational studies performed as part of routine clinical care, outcomes in RCTs are often not achieved in clinical practice [22]. However, in observational studies, certain criteria can also be applied to select patients eligible for transitioning, such as transitioning only patients with clinically stable disease. These selection criteria might affect the incidence of patients retransitioning.

Moreover, the process or strategy used to implement a biosimilar can differ between studies. Some studies extensively inform patients about transitioning and monitor their transitioned patients frequently, whereas in other studies patients are transitioned as part of routine clinical care with limited information and no extra routine visits. These differences in biosimilar implementation strategies influence a patient's experience of the transition and affect the numbers of patients who retransition [23].

Retransitioning is often a sign of treatment failure or discontent and could negatively influence the patient's treatment. In addition, retransitioning could potentially undo the financial benefits of biosimilars. Knowledge about how to introduce a biosimilar in clinical practice while minimizing the risk to patients retransitioning is therefore of value. 
The aim of this systematic review was to estimate the cumulative incidence of patients who retransitioned from $\mathrm{TNF} \alpha$ inhibitor biosimilar to originator and to explore potential patient, disease, and treatment and implementation strategy factors associated with retransitioning.

\section{Methods}

\subsection{Systematic Literature Search}

We conducted a systematic literature search in the PubMed, EMBASE, and Cochrane Central Register of controlled trials (CENTRAL) databases to identify all published articles investigating or citing TNF $\alpha$ inhibitors, biosimilar transitioning, and retransitioning. The exact search terms and medical subject heading terms used are presented in Table S1 in the electronic supplementary material (ESM). As shown in Table S1, a broad search string was applied to prevent relevant articles being missed, after which the studies found were manually checked. The systematic review was conducted according to the PRISMA (Preferred Reporting Items for Systematic Reviews and Meta-Analyses) statement [24]. The review protocol is available at PROSPERO (registration ID CRD42021226381). The search string was first executed on 19 November 2020 and was repeated on 25 March 2021 to include relevant recently published articles.

\subsection{Selection of Studies}

Studies found in the search strategy were merged in Rayyan QCRI and duplicates were removed. Only original research articles were included. Congress abstracts, reviews, editorials, and other opinion articles were excluded. The reference lists of review articles were manually checked by RM for additional potentially relevant articles not captured in the electronic search.

Titles, abstracts, and full-text publications of the identified records were screened by RM to select relevant articles, and a 5\% random sample was cross checked by HG. In case of uncertainty or disagreement, articles were discussed until consensus was reached and, if necessary, a third reviewer (TG) was consulted. Articles were included if they met the following criteria: (1) study involved transitioning from a TNF $\alpha$ inhibitor (including etanercept, infliximab, and adalimumab) originator to a biosimilar, (2) the number of patients who retransitioned was reported or could be calculated, (3) the article was an original research article published in a peer-reviewed journal, (4) the article included baseline characteristics of the patients who transitioned, (5) the article was written in English, and (6) the full-text version of the article could be obtained. Transitioning was defined as patients in whom the biosimilar was introduced after the originator, without treatment with other drugs in between. Retransitioning was defined as restarting the originator directly after discontinuing a biosimilar, without treatment with other drugs in between. In summary, transitioning was defined as switching from the originator to a biosimilar; retransitioning was defined as switching from the originator to a biosimilar and back to the originator. Both transitioning and retransitioning involved changes with the same active biological substance.

\subsection{Outcome}

The main outcome of this study was to assess the cumulative incidence of patients treated with biosimilar adalimumab, etanercept, or infliximab for any indication who retransitioned. In addition, the reasons why patients retransitioned (i.e., loss of effect, AEs, other) was collected when possible. Information about these outcomes were extracted from the publications included.

\subsection{Factors Associated with Retransitioning}

In this study, factors related to patient, disease, and treatment and implementation strategy were explored.

Factors related to patient, disease, and treatment included the following: age restrictions (only adult patients or all age categories); the therapeutic indication for which TNF $\alpha$ inhibitor was used (rheumatic disease [RD], IBD, multiple indications, or other indications); only patients with stable disease or all patients; the type of TNF $\alpha$ inhibitor (etanercept, infliximab, adalimumab, or multiple); only patients with a minimum duration of originator use or all patients.

RD included ankylosing spondylitis, chronic reactive arthritis, juvenile idiopathic arthritis, psoriatic arthritis, and rheumatoid arthritis; IBD included ulcerative colitis and Crohn's disease; and multiple indications included a combination of RD, IBD, and/or other indications for which $\mathrm{TNF} \alpha$ inhibitors are indicated. Studies were considered to only include patients with stable disease if they mentioned stable disease, low disease activity, or remission as an inclusion criterion. Minimum duration originator use was defined as having any inclusion criterion on the duration of use of originator prior to transitioning-for example, at least 6 months' use of originator-and was categorized as either only patients with a minimum duration use of originator or all patients.

Factors related to implementation strategy included the following: the manner in which information on transitioning was provided to patients (both written and verbal information from healthcare professional [HCP], only written information, only verbal information from HCP); training of HCPs (both educational and communication; only 
educational; only communicational-that is, motivational communication on transitioning); the type of consent given by patients (informed consent, opt in [patients need to grant permission to transition to a biosimilar but this is not as formal as informed consent, for example verbal permission], opt out [patients are transitioned to a biosimilar unless stated otherwise [including mandatory transitioning]); gainsharing (patients' healthcare directly benefits from financial savings from transitioning-yes or no); whether the HCP gave patients, at the time of transitioning, the option to retransition (yes or no); extra control visits to the outpatient ward (yes or no); and extra laboratory monitoring (yes or no). Extra control visits and extra laboratory monitoring were classified as such if they were explicitly mentioned as not part of routine clinical care.

Other variables assessed included baseline characteristics of the study publications, including the following: type of funding (funded by industry or publicly funded); type of study (RCT, cohort study, case-control, case series, other); geographical location of the study (continent: Europe, Asia, USA, other); the year in which patients in the study were transitioned (start of the study); duration of followup (months); randomization of patients (yes or no); blinded treatment (yes or no); and number of transitioned patients in the study. Baseline characteristics of the patients included in the studies included the following: age at transitioning $(<45,45-55,>55$ years); percentage of included females; indication; type of TNF $\alpha$ inhibitor (active substance adalimumab, etanercept, infliximab, or multiple); years since first diagnosis of disease; duration of originator treatment prior to transitioning to the biosimilar.

All data extracted from the articles were entered in a standardized data collection format created in Microsoft Excel. Data were entered by RM and cross checked by HG. In case of uncertainty or disagreement, data were discussed until consensus was reached; if necessary, a third reviewer (TG) was consulted.

\subsection{Data Analysis}

Characteristics of the studies were descriptively analyzed. In the other analyses, studies were weighted by the number of patients transitioning in the study. The primary outcomethe cumulative incidence of patients retransitioning-was plotted against the study follow-up time in a weighted dot plot to explore whether the duration of the study and cumulative incidence of patients retransitioning were correlated. The weighted dot plot presents the percentage of patients retransitioning over time, and the size of the dot represents the number of patients who initially transitioned from originator to biosimilar.

For each of the factors related to patient, disease, and treatment and implementation strategy, studies were stratified according to the categories of that factor (e.g., extra laboratory monitoring-yes or no). The weighted median (based on the number of patients who initially transitioned from originator to biosimilar) and interquartile range (IQR) of the cumulative incidence of patients who retransitioned in these studies were calculated and compared to explore whether a potential association existed between these factors and the cumulative incidence of patients who retransitioned.

\section{Results}

The systematic literature search resulted in 994 unique studies. After screening, 149 studies were identified in which patients were transitioned (originator to biosimilar) from a TNF $\alpha$ inhibitor originator to a biosimilar. Of those studies, 112 were excluded: 109 did not report on retransitioning (originator to biosimilar and back to originator), two did not report any baseline characteristics of the transitioned patients, and one was not published in a peer-reviewed journal. The remaining 37 studies were included in this systematic review (Fig. 1). The included studies and the excluded review articles $(n=98)$ were manually checked for relevant studies that were not captured in the systematic literature search, but no additional studies were included. Data extracted from the individual studies are presented in Tables $\mathrm{S} 2$ and $\mathrm{S} 3$ in the ESM.

Table 1 presents the characteristics of the included studies, in which patients were transitioned from a TNF $\alpha$ inhibitor originator to a biosimilar. The majority of included studies were publicly funded (78.4\%), included a cohort study design (97.3\%), and were performed in Europe (91.9\%). In the majority of studies, patients were transitioned in $2015(18.9 \%)$ or 2016 (35.1\%). The median follow-up was 12 months. The 37 studies included a median of 94 (IQR 45-192) patients; more than half of the studies included

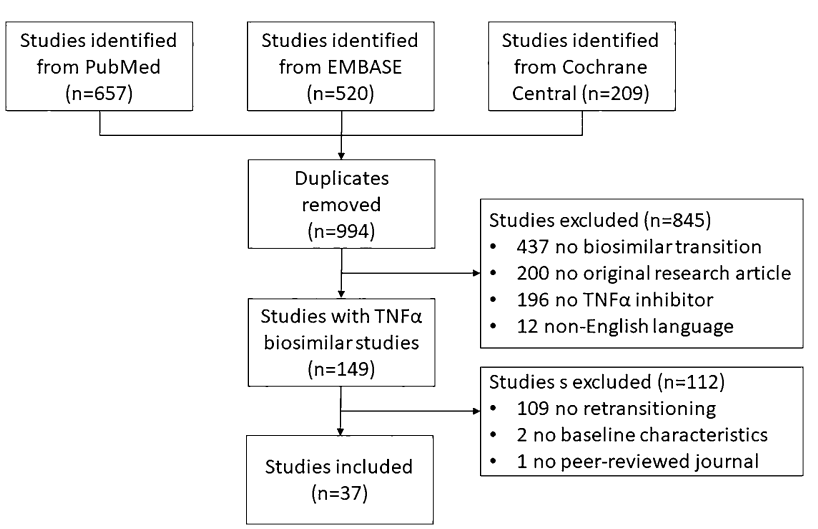

Fig. 1 Flow chart of study selection. TNF tumor necrosis factor 
Table.1 Characteristics of the included studies, in which patients were transitioned from tumor necrosis factor- $\alpha$ inhibitor originator to the corresponding biosimilar

\begin{tabular}{|c|c|}
\hline Characteristic & Publications $(n=37)$ \\
\hline \multicolumn{2}{|l|}{ Publication characteristics } \\
\hline \multicolumn{2}{|l|}{ Funding } \\
\hline Industry & $8(21.6)$ \\
\hline Public & $29(78.4)$ \\
\hline \multicolumn{2}{|l|}{ Study design characteristics } \\
\hline \multicolumn{2}{|l|}{ Type of study } \\
\hline Cohort & $36(97.3)$ \\
\hline Case series & $1(2.7)$ \\
\hline Case-control & NA \\
\hline Other & NA \\
\hline \multicolumn{2}{|l|}{ Geographical location of study } \\
\hline Europe & $34(91.9)$ \\
\hline North America (USA) & $2(5.4)$ \\
\hline Asia & $1(2.7)$ \\
\hline \multicolumn{2}{|l|}{ Year of start transitioning } \\
\hline 2012 & $1(2.7)$ \\
\hline 2013 & - \\
\hline 2014 & $3(8.1)$ \\
\hline 2015 & $7(18.9)$ \\
\hline 2016 & $13(35.1)$ \\
\hline 2017 & $5(13.5)$ \\
\hline 2018 & $4(10.8)$ \\
\hline NR & $4(10.8)$ \\
\hline Duration of follow-up, months & $12.0(6.00-15.1)$ \\
\hline Randomization of patients (yes) & $1(2.7)$ \\
\hline Treatment blinded for patients (yes) & - \\
\hline Number of patients included & $94(45-192)$ \\
\hline \multicolumn{2}{|l|}{ Study population characteristics } \\
\hline \multicolumn{2}{|l|}{ Age, years } \\
\hline$<45$ & $12(32.4)$ \\
\hline $45-55$ & $15(40.5)$ \\
\hline$>55$ & $9(24.3)$ \\
\hline Not reported & $1(2.7)$ \\
\hline$\%$ Females & $53.6 \pm 13.0$ \\
\hline \multicolumn{2}{|l|}{ Indication } \\
\hline Rheumatic disease & $22(59.5)$ \\
\hline Inflammatory bowel disease & $7(18.9)$ \\
\hline Multiple indications & $4(10.8)$ \\
\hline Other & $4(10.8)$ \\
\hline \multicolumn{2}{|l|}{ Type of TNF $\alpha$ inhibitor } \\
\hline Etanercept & $11(29.7)$ \\
\hline Infliximab & $23(62.2)$ \\
\hline Adalimumab & $2(5.4)$ \\
\hline Multiple & $1(2.7)$ \\
\hline \multicolumn{2}{|l|}{ Years since first diagnosis } \\
\hline$<10$ & $7(18.9)$ \\
\hline $10-15$ & $10(27.0)$ \\
\hline$>15$ & $6(16.2)$ \\
\hline
\end{tabular}

Table.1 (continued)

\begin{tabular}{ll}
\hline Characteristic & Publications $(n=37)$ \\
\hline Not reported & $14(37.8)$ \\
$\begin{array}{c}\text { Duration of originator treatment prior to } \\
\text { transitioning to a biosimilar, years }\end{array}$ & \\
$<5$ & $14(37.8)$ \\
$5-10$ & $14(37.8)$ \\
$>10$ & $1(2.7)$ \\
Not reported & $8(21.6)$ \\
\hline
\end{tabular}

Data are presented as $n(\%)$, mean \pm standard deviation, or median (interquartile range) unless otherwise indicated

$N A$ not applicable, $N R$ not reported, $T N F$ tumor necrosis factor

patients with an RD (59.9\%), and more than half of the studies involved patients receiving infliximab (62.2\%).

The overall weighted median cumulative incidence of patients who retransitioned (originator to biosimilar and back to originator) was 7.6\% (IQR 6.8-17.2), and the incidence did not increase with increasing follow-up time (Fig. 2). Two studies reported a much higher cumulative incidence $(50.0 \%$ [25] and $71.7 \%$ [26]) than all other studies.

As depicted in Table 2, studies that were performed in 2014,2015 , and 2016 reported the highest cumulative incidence of patients who retransitioned $(21.4 \%, 7.8 \%$, and $17.8 \%$, respectively). In studies performed later in time, the incidence decreased to $6.2 \%$ in 2017 and $4.1 \%$ in 2018 .

The reason for retransitioning was reported in 26 studies (70.3\%), which included a total of 4813 patients. Reasons for retransitioning were mainly loss of efficacy $(50.2 \%$ of patients), AEs ( $45.8 \%$ of patients), or both (3.5\% of patients). The types of AEs reported varied; infections were mentioned, as were AEs such as fatigue, headache, and malaise.

\subsection{Factors Associated with Retransitioning}

\subsubsection{Patient, Disease, and Treatment Factors}

Factors related to patient, disease, and treatment are depicted in Table 3. Studies that limited inclusion to only adult patients reported a weighted median of $6.6 \%$ of patients retransitioning compared with $8.9 \%$ in studies that included all age groups.

Two disease-related factors were evaluated in this review: the indication for which patients were treated and whether studies included only patients with stable disease or all patients. The incidence of patients who retransitioned was lowest in studies in patients with IBD compared to studies in the other indications $(6.6 \%$ for IBD vs. 15.1-17.7\%). Studies that only included patients with stable disease reported a weighted median incidence for 
Fig. 2 Weighted scatterplot of the cumulative incidence of patients who retransitioned per study

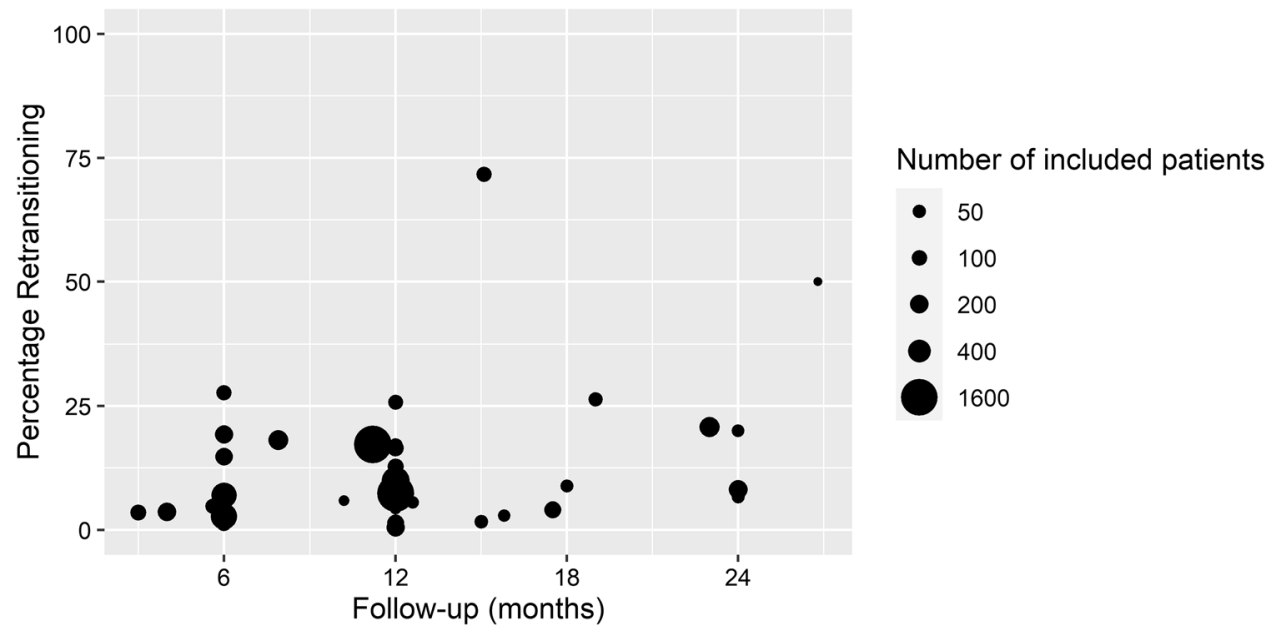

Table.2 Year of transitioning and the weighted median cumulative incidence of patients retransitioning

\begin{tabular}{lccc}
\hline $\begin{array}{l}\text { Year of } \\
\text { transition- } \\
\text { ing }\end{array}$ & $\begin{array}{l}\text { Studies, } n \\
(n=37)\end{array}$ & $\begin{array}{l}\text { Patients, } n \\
(n=855)\end{array}$ & $\begin{array}{l}\text { Median cumulative incidence } \\
\text { of patients retransitioning }\end{array}$ \\
\hline 2012 & 1 & 36 & $5.6(\mathrm{NA})$ \\
2014 & 3 & 149 & $21.4(3.4-46.6)$ \\
2015 & 7 & 1752 & $7.8(3.5-18.8)$ \\
2016 & 13 & 4869 & $17.8(11.7-19.1)$ \\
2017 & 5 & 790 & $6.2(4.8-7.6)$ \\
2018 & 4 & 370 & $4.1(2.5-6.8)$ \\
$\mathrm{NR}$ & 4 & 589 & $12.8(8.7-15.7)$ \\
\hline
\end{tabular}

$N A$ not applicable, $N R$ not reported

${ }^{\mathrm{a}}$ Data are presented as weighted \% (interquartile range)

retransitioning of $7.0 \%$ compared with $13.7 \%$ in studies that included all patients.

Studies in patients receiving adalimumab reported less retransitioning than studies with other $\mathrm{TNF} \alpha$ inhibitors (3.1 vs. 4.1-6.7\%). However, adalimumab was only evaluated in two studies, which included a limited number of patients. Studies that only included patients who had a minimum duration of use of the originator before transitioning reported a weighted median incidence of $18.3 \%$ of patients retransitioning compared with $15.1 \%$ in studies with no restrictions on duration of originator use.

\subsubsection{Implementation Strategy-Related Factors}

Several factors regarding how patients were informed about transitioning to the biosimilar were studied, as depicted in Table 4. Studies in which patients were informed about transitioning using both written information and (the option of) verbal information from their HCP reported a median incidence of retransitioning of $19.4 \%$, which is higher than that found with either one of the options ( $9.9 \%$ for only written information; $4.7 \%$ for only verbal information from the HCP); however, studies that asked for informed consent to transition reported lower incidences of patients retransitioning than did studies that asked for consent in a less formal way.

The type of training for HCPs was reported in only seven studies $(18.9 \%)$, with a total of 1074 patients included. There was no clear association between the type of training and the incidence of patients who retransitioned; the weighted median was $2.7 \%$ in studies that reported both educational and communication training, $6.8 \%$ in studies with only educational training, $25.8 \%$ in the study with only communication training, and $7.1 \%$ in studies that did not report on training to HCPs.

Studies in which patients' healthcare directly benefited from the financial gains of transitioning to a biosimilar (gainsharing) reported less retransitioning (1.4\%) than did studies that did not report gainsharing (7.2\%), although gainsharing was reported in only two studies. A higher incidence of patients who retransitioned was reported in studies that, during transitioning, offered patients the option of retransitioning if the biosimilar was not satisfactory (11.1 vs. $7.0 \%$ ).

Extra laboratory monitoring of patients after transitioning seemed to result in fewer patients retransitioning than when no extra laboratory monitoring was part of the biosimilar implementation strategy (1.6 vs. $6.1 \%$, respectively). Additional control visits did not appear to be associated with an effect on the number of patients who retransitioned.

\section{Discussion}

This systematic review studied the cumulative incidence of patients who retransitioned and the association between patient-, disease-, and treatment- and implementation 
Table.3 Patient, disease, and treatment factors, and the weighted median cumulative incidence of patients retransitioning

\begin{tabular}{|c|c|c|c|}
\hline Characteristic & $\begin{array}{l}\text { Studies, } n \\
(n=37)\end{array}$ & $\begin{array}{l}\text { Patients, } n \\
(n=8555)\end{array}$ & $\begin{array}{l}\text { Median cumulative incidence } \\
\text { of patients retransitioning }{ }^{\mathrm{a}}\end{array}$ \\
\hline \multicolumn{4}{|l|}{ Patient factors } \\
\hline \multicolumn{4}{|l|}{ Age } \\
\hline Only adult patients & 22 & 7324 & $6.6(5.7-9.1)$ \\
\hline All age categories & 15 & 1231 & $8.9(6.9-22.8)$ \\
\hline \multicolumn{4}{|l|}{ Disease factors } \\
\hline \multicolumn{4}{|l|}{ Indication } \\
\hline Rheumatic disease & 22 & 4573 & $15.1(5.4-16.0)$ \\
\hline Inflammatory bowel disease & 7 & 1556 & $6.6(0.9-8.3)$ \\
\hline Multiple indications & 4 & 2330 & $16.2(13.7-18.8)$ \\
\hline Other & 4 & 96 & $17.7(7.2-33.1)$ \\
\hline \multicolumn{4}{|l|}{ Disease stability } \\
\hline Only stable patients & 15 & 2085 & $7.0(1.5-7.1)$ \\
\hline All patients & 22 & 6470 & $13.7(8.0-21.4)$ \\
\hline \multicolumn{4}{|l|}{ Treatment factors } \\
\hline \multicolumn{4}{|l|}{ Type of TNF $\alpha$ inhibitor } \\
\hline Etanercept & 11 & 3705 & $6.5(3.7-8.0)$ \\
\hline Infliximab & 23 & 4525 & $6.7(6.7-14.2)$ \\
\hline Adalimumab & 2 & 180 & $3.1(1.2-5.1)$ \\
\hline Multiple & 1 & 145 & 4.1 (NA) \\
\hline \multicolumn{4}{|l|}{ Minimum duration use originator } \\
\hline Only patients with minimum duration of use & 13 & 3525 & $18.3(7.4-19.2)$ \\
\hline All patients & 24 & 5030 & $15.1(13.2-16.9)$ \\
\hline
\end{tabular}

$N A$ not applicable, $T N F$ tumor necrosis factor

${ }^{a}$ Data are presented as weighted \% (interquartile range)

strategy-related factors and retransitioning. The overall median cumulative incidence of retransitioning was $7.6 \%$. Retransitioning occurred to a lesser degree in patients with IBD than in those with other indications and in patients with stable disease at the start of the biosimilar. Actively offering the option to retransition resulted in more patients retransitioning than when this was not offered or reported. Extra laboratory monitoring as part of the implementation strategy resulted in fewer patients retransitioning, and gainsharing might also result in fewer patients retransitioning, although the number of studies reporting on gainsharing was very limited.

Of the studies included in this review, the vast majority (91.9\%) were performed in Europe, and only $5.4 \%$ of the studies were performed in the USA. Fewer biosimilars are registered in the USA than in Europe, and the use of biosimilars is also lower [27], which translates in clinical practice to limited experience and knowledge with biosimilars among prescribers and reluctance to prescribe a biosimilar [28]. This finding might also be explained by the different regulations: In the USA, marketing authorization holders of a biosimilar can apply for approval of their biosimilar as interchangeable with the originator by demonstrating interchangeability, and such a biosimilar can be substituted at the pharmacy level [29]. However, only one biosimilar insulin is currently approved as an interchangeable biosimilar [30], which could make practitioners reluctant to transition patients in clinical practice, thereby hampering the uptake of biosimilars. The European Medicines Agency (EMA) defines interchangeability as the possibility of exchanging one medicine for another that has the same therapeutic effect, e.g., originator to biosimilar or vice versa. The EMA does not require additional studies to show interchangeability, and decisions on interchangeability are left to the individual member states. A previous paper by EU regulators concluded that biosimilars licensed under the stringent regulatory requirements in the EU are interchangeable with their originator $[31,32]$.

We found a median cumulative incidence of retransitioning of 7.6\% (IQR 6.8-17.2). The cumulative incidence of retransitioning did not increase with increasing follow-up time, implying that retransitioning occurred mainly in the first months after transitioning to the biosimilar. As the time of follow-up does not seem to be related to the cumulative incidence calculated, we consider it appropriate to present an overall cumulative incidence for all studies together. Two 
Table.4 Implementation strategy factors and the weighted median cumulative incidence of patients retransitioning

\begin{tabular}{|c|c|c|c|}
\hline Characteristic & $\begin{array}{l}\text { Studies, } n \\
(n=37)\end{array}$ & $\begin{array}{l}\text { Patients, } n \\
(n=8555)\end{array}$ & $\begin{array}{l}\text { Median cumulative } \\
\text { incidence of patients } \\
\text { retransitioning }\end{array}$ \\
\hline \multicolumn{4}{|l|}{ Manner of providing information } \\
\hline Both written and verbal information from $\mathrm{HCP}$ & 13 & 1918 & $19.4(6.7-19.7)$ \\
\hline Written information & 1 & 758 & 9.9 \\
\hline Verbal information from $\mathrm{HCP}$ & 6 & 590 & $4.7(0.5-25.7)$ \\
\hline Not reported & 17 & 5289 & $7.4(3.6-15.2)$ \\
\hline \multicolumn{4}{|l|}{ Training of HCPs } \\
\hline Both educational and communication & 2 & 670 & $2.7(2.7-2.9)$ \\
\hline Educational & 4 & 315 & $6.8(1.4-33.4)$ \\
\hline Communication & 1 & 89 & 25.8 (NA) \\
\hline Not reported & 30 & 7481 & $7.1(5.2-10.1)$ \\
\hline \multicolumn{4}{|l|}{ Type of consent } \\
\hline Informed consent & 13 & 2189 & $1.6(1.4-7.6)$ \\
\hline Opt in & 9 & 2030 & $9.0(3.4-24.3)$ \\
\hline Opt out & 3 & 1838 & $9.7(5.0-13.1)$ \\
\hline Not reported & 12 & 2498 & $7.4(5.3-16.0)$ \\
\hline \multicolumn{4}{|l|}{ Gainsharing } \\
\hline Yes & 2 & 256 & $1.4(1.4-1.5)$ \\
\hline No & 0 & 0 & - \\
\hline Not reported & 35 & 8299 & $7.2(5.4-17.2)$ \\
\hline \multicolumn{4}{|l|}{ Option offered to retransition } \\
\hline Yes & 5 & 463 & $11.1(4.1-20.0)$ \\
\hline No & 0 & 0 & - \\
\hline Not reported & 32 & 8092 & $7.0(5.3-7.8)$ \\
\hline \multicolumn{4}{|l|}{ Extra control visits } \\
\hline Yes & 14 & 1473 & $5.4(1.6-17.5)$ \\
\hline No & 16 & 4690 & $7.1(6.8-27.8)$ \\
\hline Not reported & 7 & 2392 & $18.3(9.4-26.0)$ \\
\hline \multicolumn{4}{|l|}{ Extra laboratory monitoring } \\
\hline Yes & 15 & 2460 & $1.6(2.0-2.7)$ \\
\hline No & 12 & 3320 & $6.1(4.8-7.0)$ \\
\hline Not reported & 10 & 2775 & $5.8(3.8-13.7)$ \\
\hline
\end{tabular}

$H C P$ healthcare professional

${ }^{\mathrm{a}}$ Data are presented as weighted \% (interquartile range)

studies reported a much higher cumulative incidence of patients retransitioning than the other studies included in this review. In the study by Riller et al. [25], half of the patients retransitioned. However, this study included only eight patients, all diagnosed with neurosarcoidosis. Xue et al. [33] also reported failure of infliximab biosimilar in patients with neurosarcoidosis, with effect regained after retransitioning. The authors attributed this finding to variations in afucosylation between the originator and biosimilars, which might be associated with differences in biological activity specifically in sarcoidosis [33]. However, the effect of afucosylation variations in sarcoidosis has not been extensively studied. In the study by Yazici et al. [34] performed in Turkey, $72 \%$ of patients retransitioned. According to the authors, the incentives for the use of biosimilars are minimal in Turkey, since both originators and biosimilars are fully reimbursed [34]. However, as other countries also reimburse both originators and biosimilars, this cannot fully explain their large cumulative incidence of retransitioning. However, political factors such as the availability of the originator, regional/national policies, and pricing and reimbursement of originators and biosimilars are likely to affect the number of patients who retransition. Within the present study, we were not able to study the impact of political factors on the number of patients retransitioning. However, as the included studies covered a variety of settings with different policies on the 
implementation of biosimilars, we expect the cumulative incidence found to be representative.

We found that several factors related to patients, their disease, and their treatment could play a role in the incidence of patients who retransitioned. First, fewer patients with IBD retransitioned than those with other indications. This was a striking result: In the first years that biosimilars were available, gastroenterologists were hesitant to transition patients from originators to biosimilars [38]. However, in a qualitative study performed in Europe a few years later, gastroenterologists seemed more confident than rheumatologists about transitioning patients to biosimilars [39]; therefore, the lower numbers of retransitioning patients with IBD might be explained by the more positive opinions of gastroenterologists. This is reflected in the larger uptake of biosimilars in patients with IBD than in those with RD [40]. There were no differences between studies in patients with IBD and other indications in terms of the year the study was performed, the type of TNF $\alpha$ inhibitor, or the inclusion of only patients with stable disease; consequently, these factors did not explain the lower incidence of retransitioning in patients with IBD. Unfortunately, none of the included studies specifically studied patients with psoriasis, which is also an important indication of TNF $\alpha$ inhibitors.

Second, including only patients with stable disease appeared to be associated with less retransitioning, which might be due to attribution effects (allocating preexisting or unrelated symptoms to the change in treatment) [41]. Patients in this review who had not (yet) achieved disease stability might misattribute flares in their disease to the transition to biosimilar instead of to the natural course of their disease. In addition, only transitioning patients with stable disease from originator to biosimilar is not in line with the principle of the biosimilar being similar to the originator [42, 43].

Finally, less retransitioning was reported in studies in which patients received adalimumab than in studies of other TNF $\alpha$ inhibitors. Adalimumab was the last biosimilar to be introduced in clinical care, which could mean that the introduction of adalimumab biosimilars benefited from knowledge gained from and experience with the introduction of previous biosimilars for clinicians, pharmacists, and patients. This is supported by our finding that studies performed after 2016 reported less retransitioning.

In this review, we also studied biosimilar implementation factors. Several factors concerned issues on how patients were informed about transitioning to a biosimilar. We found that the incidence of retransitioning appeared to be increased in studies in which patients were most informed about biosimilar transitioning but decreased in studies in which patients were asked for informed consent. This seems contradictory, since informing patients well is part of obtaining informed consent. Studies in patients with IBD or RD reported that patients wished to be informed with positive and structured information on transitioning from originators to biosimilars and wanted to be actively involved in this decision $[44,45]$. However, our results demonstrate that providing more information to patients did not result in fewer patients retransitioning, which contradicts the recommendations in previous reviews [21, 46].

The two studies applying gainsharing reported a smaller incidence of retransitioning than did studies that did not report on gainsharing. In the studies that reported on gainsharing, the financial savings from transitioning to the biosimilar were used for a "long-term appointment of a switch pharmacist" [47] (not further specified) and for the appointment of IBD nurses and pharmacists for a "nurse-led IBD biologicals service for improving IBD patient safety and quality of care" [48]. Patients might be more positive about biosimilars when they directly benefit from the financial savings, but the number of studies was too limited for final conclusions. Providing patients with the option of retransitioning at the introduction of the biosimilar-if the patient is not satisfied with the biosimilar-increased the incidence of retransitioning. This finding seems logical and was also previously described [20]. In addition, the possibility of implementing gainsharing as part of transitioning patients from originators to biosimilars depends on the political situation regarding the reimbursement of biologicals.

Increased laboratory monitoring of patients after transitioning appeared to be related to fewer patients retransitioning. However, extra laboratory monitoring after transitioning did not seem to reflect the scientific principles of the biosimilar being similar to the originator [49]. The European Alliance of Associations for Rheumatology specifically states that measuring antidrug antibodies is not needed, since they do not expect an increase in antibodies after transitioning to a biosimilar [42]. However, although extra laboratory monitoring may not be justified, it could make patients feel safer and more confident in transitioning to the biosimilar and therefore prevent them from retransitioning.

This systematic review aimed to provide a complete overview of studies in which patients retransitioned to an originator after being transitioned from a TNF $\alpha$ inhibitor originator to a corresponding biosimilar. To our knowledge, this is the first review to study the incidence of retransitioning and to explore whether the numbers of patients retransitioning could be related to patient, disease, and treatment and implementation strategy factors. However, the present study contains some limitations. We extracted patient, disease, and treatment and implementation strategy factors from the included studies and categorized them as "yes" or "no". This categorization was subjective so could have been subject to interpretation errors. However, cross checking of data extraction by an independent second reviewer revealed no discrepancies, suggesting robust data collection. 
The extensiveness of reporting factors investigated in this review varied substantially in the included studies. If a factor was implemented but not reported in the study article, it was not included in this review. Some factors were only seldomly reported. In particular, implementation strategy factors were often missing. Therefore, we were unable to statistically test associations or draw any causal conclusions. To overcome this, we explanatorily analyzed associations between patient, disease, treatment, and implementation strategy factors and the cumulative incidence of retransitioning.

The results of this study present several leads in optimizing the introduction of a biosimilar TNF $\alpha$ inhibitor in clinical practice and reducing the incidence of patients retransitioning. First, as less retransitioning was seen in studies that included only patients with stable disease, clinicians might consider transitioning only such patients. Retransitioning in patients with unstable disease is probably more related to the psychological distress of transitioning than to the properties of the biosimilar. Waiting until disease is stable might solve this. Even though these patients are treated with the originator for a longer time, which is costly, it might still be beneficial in the long term, with fewer patients retransitioning.

Second, to optimize biosimilar implementation strategies, informing patients about transitioning to a biosimilar and asking for their consent to do so might improve a patient's willingness to transition. However, as this did not reduce retransitioning in the included studies, it should not be expected in clinical practice. Actively providing the option of retransitioning when commencing treatment with the biosimilar seemed to result in more patients retransitioning, so this is also not recommended. Although the reporting of gainsharing was limited, the incidence of retransitioning was substantially lower in studies that applied gainsharing, so further study of this factor could be valuable. Extra laboratory monitoring of patients seemed to result in fewer patients retransitioning. However, this seems counterintuitive from the similarity perspective and is not recommended in treatment guidelines.

Despite these recommendations of factors that may reduce the incidence of patients retransitioning, any thought of completely preventing retransitioning might be overly optimistic. The nocebo effect is often mentioned as the underlying reason for retransitioning [14, 21], and this is related to patients' lack of awareness of and misperceptions and attitudes about treatment [51, 52]. Patients' behavior and their attitudes towards treatment are influenced by their capabilities, opportunities, and motivations, as described in the COM-B (capabilities, opportunities, motivation, behavior) model $[53,54]$. To further reduce patient retransitioning, the components that define patients' behavior should be directed into a more positive attitude towards biosimilars.

\section{Conclusion}

In studies on transitioning patients from $\mathrm{TNF} \alpha$ originator to biosimilars with a median 12 months of follow-up, $8 \%$ of patients retransitioned. Retransitioning appeared to be lower in studies that included only patients with stable disease, in studies that did not offer patients the option of retransitioning at the introduction of the biosimilar, and in studies that applied extra laboratory monitoring as part of the implementation strategy. Clinicians could consider implementing these factors to reduce the numbers of patients retransitioning to the originator and improve the introduction of biosimilars in clinical practice.

Supplementary Information The online version contains supplementary material available at https://doi.org/10.1007/s40259-021-00508-4.

\section{Declarations}

Funding This research did not receive any specific grant from funding agencies in the public, commercial, or not-for-profit sectors.

Conflicts of interest Rosanne W. Meijboom, Helga Gardarsdottir, Toine C.G. Egberts, and Thijs J. Giezen have no conflicts of interest that are directly relevant to the content of this article.

Data availability All data generated or analyzed during this study are included in this published article and its supplementary information files.

Ethics approval Not applicable.

Consent to participate Not applicable.

Consent for publication Not applicable.

Author contributions HG, TE, TG, and RM contributed to the study conception and design. RM collected data, which was cross checked by HG. Data analysis and interpretation were performed by HG, TE, TG, and RM. The manuscript was drafted and critically revised by HG, TE, TG, and RM. All authors approved the final version of the manuscript.

Open Access This article is licensed under a Creative Commons Attribution-NonCommercial 4.0 International License, which permits any non-commercial use, sharing, adaptation, distribution and reproduction in any medium or format, as long as you give appropriate credit to the original author(s) and the source, provide a link to the Creative Commons licence, and indicate if changes were made. The images or other third party material in this article are included in the article's Creative Commons licence, unless indicated otherwise in a credit line to the material. If material is not included in the article's Creative Commons licence and your intended use is not permitted by statutory regulation or exceeds the permitted use, you will need to obtain permission directly from the copyright holder. To view a copy of this licence, visit http://creativecommons.org/licenses/by-nc/4.0/. 


\section{References}

1. Harbord M, et al. Third European evidence-based consensus on diagnosis and management of ulcerative colitis. Part 2: current management. J Crohn's Colitis. 2017;11(7):769-84. https://doi. org/10.1093/ecco-jcc/jjx009.

2. Gomollón F, et al. 3rd European evidence-based consensus on the diagnosis and management of Crohn's disease 2016: part 1: diagnosis and medical management. J Crohn's Colitis. 2017;11(1):325. https://doi.org/10.1093/ecco-jcc/jjw168.

3. Smolen JS, et al. EULAR recommendations for the management of rheumatoid arthritis with synthetic and biological disease-modifying antirheumatic drugs: 2016 update. Ann Rheum Dis. 2017;76(6):960-77. https://doi.org/10.1136/annrh eumdis-2016-210715.

4. European Medicines Agency. Guideline on similar biological medicinal products. 2014

5. Crosby M, Tadrous M, Gomes T. Potential cost implications of mandatory non-medical switching policies for biologics for rheumatic conditions and inflammatory bowel disease in Canada. Clin Pharmacol Ther. 2020. https://doi.org/10.1002/ cpt.2042.

6. Remsima. Summary of product characteristics. EMA. 2019;2019(167-172):2019. https://doi.org/10.2307/j.ctvdf0dxq. 12.

7. Food and Drug Administration (FDA). Biosimilar product information. 2020. https://www.fda.gov/drugs/biosimilars/biosimilarproduct-information.

8. European Medicines Agency. Product Information Benepali (etanercept); 2019. pp. 167-72. https://doi.org/10.2307/j.ctvdf 0dxq.12.

9. Imraldi. Summary of product characteristics. EMA. 2019;2019:167-72. https://doi.org/10.2307/j.ctvdf0dxq.12.

10. Yoo DH, et al. A randomised, double-blind, parallel-group study to demonstrate equivalence in efficacy and safety of CT-P13 compared with innovator infliximab when coadministered with methotrexate in patients with active rheumatoid arthritis: the PLANETRA study. Ann Rheum Dis. 2013;72(10):1613-20. https://doi. org/10.1136/annrheumdis-2012-203090.

11. Emery P, et al. A phase III randomised, double-blind, parallelgroup study comparing SB4 with etanercept reference product in patients with active rheumatoid arthritis despite methotrexate therapy. Ann Rheum Dis. 2017;76(1):51-7. https://doi.org/10. 1136/annrheumdis-2015-207588.

12. Weinblatt ME, et al. Phase III randomized study of SB5, an adalimumab biosimilar, versus reference adalimumab in patients with moderate-to-severe rheumatoid arthritis. Arthritis Rheumatol. 2018;70(1):40-8. https://doi.org/10.1002/art.40336.

13. Jørgensen KK, et al. Switching from originator infliximab to biosimilar CT-P13 compared with maintained treatment with originator infliximab (NOR-SWITCH): a 52-week, randomised, doubleblind, non-inferiority trial. Lancet. 2017;389(10086):2304-16. https://doi.org/10.1016/S0140-6736(17)30068-5.

14. Barbier L, Ebbers H, Simoens S, Declerck P, Vulto A, Huys I. The efficacy, safety and immunogenicity of switching between reference biopharmaceuticals and biosimilars: a systematic review. Clin Pharmacol Ther. 2020;21:S309. https://doi.org/10.1016/j. jval.2018.09.1840.

15. Glintborg B, et al. To switch or not to switch: results of a nationwide guideline of mandatory switching from originator to biosimilar etanercept. One-year treatment outcomes in 2061 patients with inflammatory arthritis from the DANBIO registry. Ann Rheum Dis. 2019;78(2):192-200. https://doi.org/10.1136/annrh eumdis-2018-213474.
16. Tweehuysen L, et al. Open-label, non-mandatory transitioning from originator etanercept to biosimilar SB4: six-month results from a controlled cohort study. Arthritis Rheumatol. 2018;70(9):1408-18. https://doi.org/10.1002/art.40516.

17. Guerra-Veloz MF, et al. Loss of efficacy and safety of the switch from infliximab original to infliximab biosimilar (CT-P13) in patients with inflammatory bowel disease. World J Gastroenterol. 2018;24(46):5288-96. https://doi.org/10.3748/wjg.v24.i46.5288.

18. Xue L, et al. Are patients at risk for recurrent disease activity after switching from remicade ${ }^{\circledR}$ to Remsima ${ }^{\circledR}$ ? An Observational Study. Front Med. 2020;7:1-10. https://doi.org/10.3389/fmed. 2020.00418.

19. Scherlinger M, et al. Switching from originator infliximab to biosimilar CT-P13 in real-life: the weight of patient acceptance. Jt Bone Spine. 2018. https://doi.org/10.1016/j.jbspin.2017.10.003.

20. Müskens WD, Rongen-van-Dartel SAA, Teerenstra S, Adang EMM, van Riel PLCM. One-year results after transitioning from etanercept originator to biosimilar in a setting promoting shared decision-making in rheumatology. Rheumatol Adv Pract. 2020;4(2):rkaa02. https://doi.org/10.1093/rap/rkaa042.

21. Odinet JS, Day CE, Cruz JL, Heindel GA. The Biosimilar Nocebo Effect? A systematic review of double-blinded versus open-label studies. J Manag Care Spec Pharm. 2018;24:10.

22. Kilcher G, Hummel N, Didden EM, Egger M, Reichenbach S. Rheumatoid arthritis patients treated in trial and real world settings: comparison of randomized trials with registries. Rheumatol (UK). 2018;57(2):354-69. https://doi.org/10.1093/rheumatology/ kex394.

23. Pouillon L, et al. Consensus report: clinical recommendations for the prevention and management of the nocebo effect in biosimilartreated IBD patients. Aliment Pharmacol Ther. 2018;1-7:2019. https://doi.org/10.1111/apt.15223.

24. Moher D, et al. Preferred reporting items for systematic reviews and meta-analyses: the PRISMA statement. PLoS Med. 2009;6:7. https://doi.org/10.1371/journal.pmed.1000097.

25. Riller Q, et al. Infliximab biosimilar for treating neurosarcoidosis: tolerance and efficacy in a retrospective study including switch from the originator and initiation of treatment. J Neurol. 2019;266(5):1073-8. https://doi.org/10.1007/ s00415-019-09234-y.

26. Yazici Y, et al. Analysis of real-world treatment patterns in a matched rheumatology population that continued innovator infliximab therapy or switched to biosimilar infliximab. Biologics. 2018;12:127-34. https://doi.org/10.2147/BTT.S172337.

27. Mehr SR, Brook RA. Biosimilars in the USA: will new efforts to spur approvals and access spur uptake and cost savings? Pharmaceut Med. 2019;33(1):1-8. https://doi.org/10.1007/ s40290-018-00262-z.

28. Kolbe AR, et al. Physician understanding and willingness to prescribe biosimilars: findings from a US national survey. BioDrugs. 2021;2021:0123456789. https://doi.org/10.1007/ s40259-021-00479-6.

29. US Department of Health and Human Services, Food and Drug Administration (FDA), Center for Drug Evaluation and Research (CDER), and Center for Biologics Evaluation and Research (CBER), considerations in demonstrating interchangeability with a reference product-guidance for industry. 2019. p. 23.

30. Food and Drug Administration (FDA). FDA approves first interchangeable biosimilar insulin product for treatment of diabetes. 2021. https://www.fda.gov/news-events/press-announcements/ fda-approves-first-interchangeable-biosimilar-insulin-producttreatment-diabetes.

31. European Medicines Agency. Biosimilars in the EU- Information guide for healthcare professionals. Prepared jointly by the European Medicines Agency and the European Commission, (CEuropean Med. Agency, pp. 1-40. 2019. [Online]. https://www. 
ema.europa.eu/en/documents/leaflet/biosimilars-eu-informationguide-healthcare-professionals_en.pdf.

32. Kurki P, van Aerts L, Wolff-Holz E, Giezen T, Skibeli V, Weise M. Interchangeability of biosimilars: a European perspective. BioDrugs. 2017;31(2):83-91. https://doi.org/10.1007/ s40259-017-0210-0.

33. Xue L, et al. Are patients at risk for recurrent disease activity after switching from remicade( $(\circledR)$ to Remsima $(\circledR)$ ? An observational study. Front Med. 2020;7:418. https://doi.org/10.3389/fmed.2020. 00418.

34. Yazici Y, Xie L, Ogbomo A, Ellis LA, Goyal K, Teeple A, Mutlu EA. A descriptive analysis of real-world treatment patterns of innovator (Remicade $($ ) ) and biosimilar infliximab in an infliximab-naïve Turkish population. Biol Targets Ther. 2018;12:97106. https://doi.org/10.2147/BTT.S172241.

35. Deaner JD, et al. Recurrence rates of inflammation after switching from originator infliximab to biosimilar infliximab-abda for non-infectious uveitis. Am J Ophthalmol. 2020. https://doi.org/ 10.1016/j.ajo.2020.08.005.

36. Ratnakumaran R, et al. Efficacy and tolerability of initiating, or switching to, infliximab biosimilar CT-P13 in inflammatory bowel disease (IBD): a large single-centre experience. Scand J Gastroenterol. 2018;53(6):700-7. https://doi.org/10.1080/00365521.2018. 1464203.

37. Tapete G, et al. Effectiveness and safety of nonmedical switch from adalimumab originator to SB5 biosimilar in patients with inflammatory bowel diseases: twelve-month follow-up from the TABLET registry. Inflamm Bowel Dis. 2021. https://doi.org/10. 1093/ibd/izab027.

38. Danese S, Gomollon F. ECCO position statement: the use of biosimilar medicines in the treatment of inflammatory bowel disease (IBD). J Crohn's Colitis. 2013;7(7):586-9. https://doi.org/ 10.1016/j.crohns.2013.03.011.

39. Aladul MI, Fitzpatrick RW, Chapman SR. Healthcare professionals' perceptions and perspectives on biosimilar medicines and the barriers and facilitators to their prescribing in UK: a qualitative study. BMJ Open. 2018;8(11):e023603. https://doi.org/10.1136/ bmjopen-2018-023603.

40. Kanters TA, Stevanovic J, Huys I, Vulto AG, Simoens S. Adoption of biosimilar infliximab for rheumatoid arthritis, ankylosing spondylitis, and inflammatory bowel diseases in the EU5: a budget impact analysis using a Delphi panel. Front Pharmacol. 2017;8:322. https://doi.org/10.3389/fphar.2017.00322.

41. Faasse K, Petrie KJ. The nocebo effect: patient expectations and medication side effects. Postgrad Med J. 2013;89(1055):540-6. https://doi.org/10.1136/postgradmedj-2012-131730.

42. Kay J, et al. Consensus-based recommendations for the use of biosimilars to treat rheumatological diseases. Ann Rheum Dis. 2018;77(2):165-74. https://doi.org/10.1136/annrh eumdis-2017-211937.

43. Danese S, et al. ECCO Position statement on the use of biosimilars for inflammatory bowel disease-an update. J Crohn's Colitis. 2017;11(1):26-34. https://doi.org/10.1093/ecco-jcc/jjw198.

44. Armuzzi A, Avedano L, Greveson K, Kang T. Nurses are critical in aiding patients transitioning to biosimilars in inflammatory bowel disease: education and communication strategies. J Crohn's Colitis. 2019;13(2):259-66. https://doi.org/10.1093/ecco-jcc/ jjy 150.

45. Scherlinger M, Langlois E, Germain V, Schaeverbeke T. Acceptance rate and sociological factors involved in the switch from originator to biosimilar etanercept (SB4). Semin Arthritis Rheum. 2019;48(5):927-32. https://doi.org/10.1016/j.semarthrit.2018.07. 005 .

46. Kristensen LE, et al. Non-pharmacological effects in switching medication: the Nocebo effect in switching from originator to biosimilar agent. BioDrugs. 2018. https://doi.org/10.1007/ s40259-018-0306-1.

47. Chan A, Kitchen J, Scott A, Pollock D, Marshall R, Herdman L. Implementing and delivering a successful biosimilar switch programme - the Berkshire West experience. Futur Healthc J. 2019;6(2):143-5. https://doi.org/10.7861/futurehosp.6-2-143.

48. Razanskaite $\mathrm{V}$, et al. Biosimilar infliximab in inflammatory bowel disease: outcomes of a managed switching programme. J Crohns Colitis. 2017;11(6):690-6. https://doi.org/10.1093/ecco-jcc/ jjw216.

49. European Medicines Agency. Guideline on similar biological medicinal products. 2014. https://www.ema.europa.eu/en/ documents/scientific-guideline/guideline-similar-biologicalmedicinal-products-rev1_en.pdf.

50. Colloca L, Panaccione R, Murphy TK. The clinical implications of nocebo effects for biosimilar therapy. Front Pharmacol. 2019;10:1-11. https://doi.org/10.3389/fphar.2019.01372.

51. Kravvariti E, Kitas GD, Mitsikostas DD, Sfikakis PP. Nocebos in rheumatology: emerging concepts and their implications for clinical practice. Nat Rev Rheumatol. 2018. https://doi.org/10. 1038/s41584-018-0110-9.

52. Michie S, van Stralen MM, West R. The behaviour change wheel: a new method for characterising and designing behaviour change interventions. Implement Sci. 2011;6(1):42. https://doi. org/10.1186/1748-5908-6-42.

53. Jackson C, Eliasson L, Barber N, Weinman J. Applying COM-B to medication adherence work tended to focus on the role and its effects on patient. Eur Heal Psychol. 2014;16(1):7-17.

54. Abdalla A, et al. Long-term safety and efficacy of biosimilar infliximab among patients with inflammatory arthritis switched from reference product. Open Access Rheumatol Res Rev. 2017;9:29-35. https://doi.org/10.2147/OARRR.S124975.

55. Al-Tabaa O, et al. Doctor's aptitude for switching from innovator etanercept to biosimilar etanercept in inflammatory rheumatic diseases: experience from a single French rheumatology tertiary care center. Eur J Clin Pharmacol. 2020. https://doi.org/ 10.1007/s00228-020-02957-2.

56. Avouac J, et al. Systematic switch from innovator infliximab to biosimilar infliximab in inflammatory chronic diseases in daily clinical practice: the experience of Cochin University Hospital, Paris, France. Semin Arthritis Rheum. 2018;47(5):741-8. https://doi.org/10.1016/j.semarthrit.2017.10.002.

57. Binkhorst L, Sobels A, Stuyt R, Westerman EM, West RL. Short article: Switching to a infliximab biosimilar: short-term results of clinical monitoring in patients with inflammatory bowel disease. Eur J Gastroenterol Hepatol. 2018;30(7):699-703. https:// doi.org/10.1097/MEG.0000000000001113.

58. Boone NW, et al. The nocebo effect challenges the nonmedical infliximab switch in practice. Eur J Clin Pharmacol. 2018;74(5):655-61. https://doi.org/10.1007/ s00228-018-2418-4.

59. Bruni BFMM-C, Gentileschi S, Pacini G, Baldi C, Capassoni M, Tofani L, Bardelli M, Cometi L, Cantarini L, Nacci F, Vietri M, Bartoli F, Fiori G. The switch from etanercept originator to SB4: data from a real-life experience on tolerability and persistence on treatment in joint inflammatory diseases. Ther Adv Musculoskelet Dis. 2018;9(6):259-61.

60. Bruni C, et al. Efficacy and safety of switching from reference adalimumab to SB5 in a real-life cohort of inflammatory rheumatic joint diseases. Clin Rheumatol. 2021;40(1):85-91. https:// doi.org/10.1007/s10067-020-05199-w.

61. Chan A, Kitchen J, Scott A, Pollock D, Marshall R, Herdman L. Implementing and delivering a successful biosimilar switch programme - the Berkshire West experience. Futur Healthcare J. 2019;6(2):143-5. https://doi.org/10.7861/futurehosp.6-2-143. 
62. Deaner JD, et al. Recurrence rates of inflammation after switching from the originator infliximab to biosimilar infliximab-abda for noninfectious uveitis. Am J Ophthalmol. 2020. https://doi.org/10. 1016/j.ajo.2020.08.005.

63. Ditto MC, et al. Efficacy and safety of a single switch from etanercept originator to etanercept biosimilar in a cohort of inflammatory arthritis. Sci Rep. 2020;10(1):16178. https://doi.org/10.1038/ s41598-020-73183-0.

64. Kaltsonoudis E, Pelechas E, Voulgari PV, Drosos AA. Maintained clinical remission in ankylosing spondylitis patients switched from reference infliximab to its biosimilar: an 18-month comparative open-label study. J Clin Med. 2019;8:7. https://doi.org/ 10.3390/jcm8070956.

65. Felis-Giemza A, et al. Observational study of inflammatory arthritis treatment by etanercept originator switched to an etanercept biosimilar. Reumatologia. 2019;57(5):257-63. https://doi.org/10. 5114/reum.2019.89516.

66. Fitzgerald T, et al. Switching and discontinuation patterns among patients stable on originator infliximab who switched to an infliximab biosimilar or remained on originator infliximab. Biol Targets Ther. 2021;15:1-15. https://doi.org/10.2147/btt.s285610.

67. Park M-C, et al. Long-term efficacy, safety and immunogenicity in patients with rheumatoid arthritis continuing on an etanercept biosimilar (LBEC0101) or switching from reference etanercept to LBEC0101: an open-label extension of a phase III multicentre, randomised, doub. Arthritis Res Ther. 2019;21(1):122. https://doi. org/10.1186/s13075-019-1910-2.

68. Kiltz U, Tsiami S, Baraliakos X, Braun J. Non-medical switching from originator to biosimilar etanercept-no evidence for a relevant nocebo effect-a retrospective analysis of real-life data. Clin Exp Rheumatol. 2020;716-717:2020. https://doi.org/10. 1136/annrheumdis-2019-eular.2419.

69. Kumar N, Follestad T, Sen HN, Austeng D. A systematic switch from originator infliximab to biosimilar infliximab in patients with non-infectious uveitis. Am J Ophthalmol. 2020;1-7:2020. https:// doi.org/10.1016/j.ajo.2020.10.013.

70. Lauret A, et al. Effects of successive switches to different biosimilars infliximab on immunogenicity in chronic inflammatory diseases in daily clinical practice. Semin Arthritis Rheum. 2020;50(6):1449-56. https://doi.org/10.1016/j.semarthrit.2020. 02.007 .

71. Layegh Z, et al. Efficacious transition from reference infliximab to biosimilar infliximab in clinical practice. Int J Rheum Dis. 2019;22(5):869-73. https://doi.org/10.1111/1756-185X.13512.

72. Madenidou CR, Jeffries A, Varughese S, Jones S, Sari-Kouzel H, Veevers $\mathrm{H}$. Switching patients with inflammatory arthritis from
Etanercept (Enbrel®) to the biosimilar drug, SB4 (Benepali® ): a single-centre retrospective observational study in the UK and a review of the literature. Mediterr J Rheumatol. 2017;28(4):223-6.

73. Mahmmod S, et al. Outcome of reverse switching from CT-P13 to originator infliximab in patients with inflammatory bowel disease. Inflamm Bowel Dis. 2021. https://doi.org/10.1093/ibd/izaa364.

74. Müskens WD, Rongen-van-Dartel SAA, Teerenstra S, Adang EMM, van Riel PLCM. One-year results after transitioning from etanercept originator to biosimilar in a shared decision-making promoting setting in rheumatology. Rheumatol Adv Pract. 2020;1-7:2020. https://doi.org/10.1093/rap/rkaa042.

75. Nikiphorou E, et al. Clinical effectiveness of CT-P13 (Infliximab biosimilar) used as a switch from Remicade (infliximab) in patients with established rheumatic disease. Report of clinical experience based on prospective observational data. Expert Opin Biol Ther. 2015;15(12):1677-83. https://doi.org/10.1517/14712 598.2015.1103733.

76. Petit J, et al. Multidisciplinary team intervention to reduce the nocebo effect when switching from the originator infliximab to a biosimilar. RMD Open. 2021;7(1):1-9. https://doi.org/10.1136/ rmdopen-2020-001396.

77. Provenzano G, Arcuri C, Miceli MC. Open-label non-mandatory transitioning from originators to biosimilars in routine clinical care. Clin Rheumatol. 2021;40(1):425-7. https://doi.org/10.1007/ s10067-020-05327-6.

78. Scherlinger M, et al. Switching from originator infliximab to biosimilar CT-P13 in real-life: the weight of patient acceptance. Jt Bone Spine. 2018;85(5):561-7. https://doi.org/10.1016/j.jbspin. 2017.10.003.

79. Schmitz EMH, et al. Switching from infliximab innovator to biosimilar in patients with inflammatory bowel disease: a 12-month multicentre observational prospective cohort study. Aliment Pharmacol Ther. 2018;47(3):356-63. https://doi.org/10.1111/apt. 14453.

80. Selmi C, et al. BENEFIT: real-world effectiveness of SB4 after transition from reference etanercept in rheumatoid arthritis and axial spondyloarthritis. Clin Exp Rheumatol. 2020;2020:1.

81. Tweehuysen L, et al. Subjective complaints as the main reason for biosimilar discontinuation after open-label transition from reference infliximab to biosimilar infliximab. Arthritis Rheumatol. 2018;70(1):60-8. https://doi.org/10.1002/art.40324.

82. Valido A, et al. Efficacy, immunogenicity and cost analysis of a systematic switch from originator infliximab to biosimilar CT-P13 of all patients with inflammatory arthritis from a single center. Acta Reumatol Port. 2019;44(4):303-11.

\section{Authors and Affiliations}

\section{Rosanne W. Meijboom ${ }^{1,2} \cdot$ Helga Gardarsdottir ${ }^{2,3,4} \cdot$ Toine C. G. Egberts $^{2,3} \cdot$ Thijs J. Giezen $^{1,2,5}$ (D)}

Thijs J. Giezen

tgiezen@sahz.nl

1 Pharmacy Foundation of Haarlem Hospitals, Haarlem, The Netherlands

2 Division of Pharmacoepidemiology and Clinical Pharmacology, Utrecht Institute for Pharmaceutical Sciences, Utrecht, The Netherlands
3 Department of Clinical Pharmacy, University Medical Center Utrecht, Utrecht, The Netherlands

4 Department of Pharmaceutical Sciences, University of Iceland, Reykjavík, Iceland

5 Department of Clinical Pharmacy, Spaarne Gasthuis, Haarlem and Hoofddorp, The Netherlands 